EDITORIAL

\title{
Overview of Medical Education Unit (MEU), AKMMC
}

\author{
*MM Rahman ${ }^{1}$ \\ 1Prof. Dr. Md. Mahfuzar Rahman, Head, Department of community medicine \& \\ Academic Coordinator, AKMMC
}

*Corresponding author

The fundamental purpose of medical education is to enable the student to think and act clinically at a define level of competence leading to a career in general or specialty in professional development to deal with health problems of the population both healthy \& sick in a holistic views.

Many medical institutions around the world have well established MEUs. The first unit started from 1958, and until 1970s there were only 72 MEUs worldwide. ${ }^{1}$ In the UK, several MEUs were set up during 1970 s to support the undergraduate curriculum and to act as a national resource in medical education. ${ }^{2}$ However, in the USA, as of 2001 there were 61 formal MEU. ${ }^{3}$ The establishment of MEUs has several positive effects. It enhances quality of medical education, increases the publication of scholarly articles as well as educational research. The unit continues to provide important benefits to the education mission of the institution by supporting professional scholars to the continued development of medical education as a discipline. In Bangladesh the MEUs are functioning in government medical colleges in early 1990s. The functions of MEUs vary from institution to institution in regards to their scope of activities in undergraduate \& professional education in particular.

Medical Education Unit (MEU) of Anwer Khan Modern Medical College is responsible for maintenance of ongoing MBBS curriculum in this country. It investigates implementation of curriculum activities in different phases of teaching learning activities of the institution in particular. It operates its activities from the year 2010. It builds on a platform of innovation \& education leadership. It comprises a body in response to various reforms like faculty development through dissemination of series of teaching methodology programs among faculties of clinical, pre \& para-clinical disciplines. It has a body of staff with specialist $\&$ profession having interest in education from a diverse range of senior teachers.
The MEU investigates learning \& teaching activities of the institution including preparation of lesson plan, assessment \& evaluation with emphasis on students feed back in response to teaching program delivered by various disciplines to take appropriate measures towards improvement. The unit is committed to undertake interdisciplinary research to inform education of future doctors. The faculties of the disciplines investigate the aspects of health professional education in tutorial, clinical, and health care of the community settings as well. Our vision is to undertake research in a broad range of areas related to the need based curriculum development, implementation \& evaluation of entry to practice and priority issues medical programs. We do prepare our faculty to share our educational program to other private medical colleges of the country in future. We are committed to prepare annual report highlighting the academic activities of the institution for onward transmission to the government regularly. We maintain a very close relation with Centre for Medical Education (CME) of the government in developing \& delivering the curriculum of the MBBS course mostly. We use information technologies such as websites to improve access and engagement with curriculum, teaching materials and activities. We are looking for the collaborative funding sources apart from government for educational research \& teaching learning activities. Several factors have contributed to the success of MEU $\&$ its establishment in this institution is seen to have positive effect in implementing MBBS curriculum as well as development of faculty mostly.

\section{Reference}

1. Council of Medical Education Task force on Medical School Objectives June, 1998

2. Al-Wardy NM, Medical Education Units- history, functions, and organization. Sulatan Qaboos University medical journal July 2008; 8 (2): 149-156

3. From http://medicine. unimelb.edu.au/research $/ \mathrm{s}$ ummaries/medical_education 